\title{
Realidade Aumentada em Geografia: uma atividade de orientação no ensino fundamental
}

Fabrício Herpich, PPGIE, UFRGS, fabricio_herpich@hotmail.com

Felipe Becker Nunes, PPGIE, UFRGS, nunesfb@gmail.com

Gleizer Bierhalz Voss, PPGIE, UFRGS, gleizer.voss@iffarroupilha.edu.br

Paulo Sindeaux, CMPA, paulo.sindeaux@gmail.com

Liane Margarida Rockenbach Tarouco,PPGIE, UFRGS, liane@penta.ufrgs.br

José Valdeni De Lima, PPGIE, UFRGS, valdeni@inf.ufrgs.br

\begin{abstract}
Resumo. Este artigo tem como objetivo apresentar uma atividade de orientação para auxiliar no processo de ensino-aprendizagem de Geografia através do uso de realidade aumentada (RA). Para tanto, foi conduzida uma pesquisa nãoexperimental com estudantes do $6^{\circ}$ ano do ensino fundamental de uma instituição de ensino pública. Os resultados alcançados evidenciaram que os participantes consideraram a abordagem positiva e que a estratégia utilizada com a atividade de orientação, combinada com o uso de acessórios tecnológicos, não só colaborou com a visualização do conteúdo como também permitiu estabelecer a relação entre teoria e prática.
\end{abstract}

Palavras-chave: Geografia; Realidade Aumentada; Dispositivos Móveis.

\section{Augmented Reality in Geography: an orientation activity in elementary education}

\begin{abstract}
This article aims to present an orientation activity to assist in the teaching-learning process of Geography using of augmented reality. Therefore, a non-experimental research was conducted with students of the 6th year of elementary school in a public educational institution. The results showed that the participants considered the approach to be positive and that the strategy used with the orientation activity, combined with the use of technological accessories, not only contributed to the visualization of the content but also allowed to establish the relationship between theory and practice.
\end{abstract}

Keywords: Geography; Augmented Reality; Mobile Devices.

\section{INTRODUÇÃO}

A disciplina de Geografia é um componente curricular do ensino fundamental onde os alunos são motivados a estudar as ciências naturais (e.g. geologia, oceanografia e climatologia) e ciências sociais (e.g. economia e sociologia) (Netto et al., 2016). Nesta disciplina, tradicionalmente os conteúdos são abordados de uma forma mais expositiva, em que o aluno atua essencialmente como um receptor de informações.

Neste contexto, Webster e Hackley (1997) entendem que, de maneira geral, os professores podem ser considerados como os atores principais neste tipo de abordagem, considerada mais tradicional. Entretanto, ao longo dos últimos anos, a inserção das Tecnologias da Informação e Comunicação no meio educacional tem auxiliado a alterar 
progressivamente este cenário, em que o uso de ambientes virtuais de aprendizagem, jogos educacionais, realidade aumentada e dispositivos móveis tem auxiliado a modificar a forma de ensino de conteúdos na área de Geografia.

Os jogos educacionais estão dentre essas alternativas, sejam digitais ou nãodigitais, visto que são ferramentas capazes de disseminar informações e estimular a atenção dos alunos, ao mesmo tempo em que os motivam através de atividades de competição e cooperação (Calisto et al., 2010). Neste sentido, uma maneira de proporcionar e/ou reforçar o ensino de conteúdos, auxiliando os alunos no pleno entendimento dos mesmos, consiste no uso de jogos educacionais não-digitais, e.g. tabuleiros, cartas e opções mais envolventes como competições entre equipes.

Para a área de geografia, um exemplo de uso educacional de jogos não-digitais consiste na realização de uma atividade de orientação, a qual favorece a prática dos alunos de forma mais ativa em relação aos conhecimentos construídos no decorrer da disciplina, referentes aos tópicos de cartografia, pontos cardeais e localização geográfica. Do mesmo modo, Sabota et al. (2013) corroboram afirmando que o emprego desta prática no ensino de geografia, faz com que os conteúdos façam mais sentido e recebam maior notoriedade do aprendiz, pois possibilita ao estudante visualizar a utilização na prática do conceito visto em sala de aula, os quais são empregados na realização da atividade e na superação dos desafios que são apresentados, até o término da competição.

Diante das asserções discutidas nesta seção, este artigo tem como objetivo apresentar a realização de uma atividade de orientação com estudantes do Colégio Militar de Porto Alegre, com o intuito de contribuir na aplicação prática e reflexão dos conhecimentos construídos nas aulas de Geografia. Para tanto, criou-se um ambiente de competição entre os participantes, através da configuração de um jogo com pontuações e premiações, em que o grupo vencedor seria o que realizasse a atividade em menor tempo e com menor número de dicas solicitadas.

Além das técnicas de gamificação empregadas na atividade de orientação, outra estratégia implementada para envolver os estudantes, foi o uso de dispositivos móveis com um aplicativo desenvolvido para essa atividade, contendo recursos de realidade aumentada. A aplicação foi instalada nos dispositivos móveis, com a finalidade de serem utilizados pelos alunos no decorrer da atividade, dentro do espaço do colégio, onde também foram adicionados marcadores em diferentes pontos físicos da instituição, os quais deveriam ser encontrados pelos alunos para que pudessem responder aos desafios e receber as instruções para as próximas etapas. Por fim, um modelo de avaliação de jogos educacionais foi utilizado para avaliar a qualidade do jogo e analisar os resultados provenientes do experimento realizado.

\section{REALIDADE AUMENTADA}

A realidade aumentada consiste na integração de recursos virtuais com elementos físicos do mundo real, em que os elementos gráficos concebidos através de computador são apresentados nos dispositivos tecnológicos dos usuários, simultaneamente com os elementos do ambiente real em que se encontram. Conforme Thomaz et al. (2005), a RA trata da inserção de objetos virtuais no mundo real por meio de um dispositivo computacional, de forma que a interface do usuário se torna aquela utilizada no mundo real, adaptada para visualizar e manipular os objetos virtuais colocados no seu espaço. 
Por sua vez, Kato et al. (2014) enfatizam que a RA oferece um conjunto diferenciado de características, e assim, pode ser usada de forma diferente das demais tecnologias na área educativa, sendo algumas dessas características a inserção de anotações no mundo real, visualização contextualizada, ótica e háptica.

No contexto desta pesquisa, além das características já elencadas, a RA foi utilizada pelo seu potencial em complementar os jogos educacionais, uma vez que possibilita explorar uma série de recursos virtuais para um viés educacional, acrescentando aos jogos educacionais, por exemplo, a apresentação em escala de elementos virtuais tridimensionais, além de permitir o mapeamento de globos terrestres, o uso de bússolas, a identificação de marcadores, entre outras funcionalidades.

\section{ESTUDO DE CASO}

Além de ser considerada uma modalidade esportiva, a atividade de orientação também é frequentemente utilizada como uma prática pedagógica no ensino de Geografia, com o intuito de auxiliar o processo de ensino-aprendizagem dos conceitos relacionados à cartografia, orientação e localização, bem como as habilidades espaciais inerentes à atividade, através de uma atividade lúdica e envolvente, na qual o participante precisa refletir sobre as instruções que são apresentadas (e.g., pontos cardeais e orientações geográficas), para então encontrar as próximas fases/localizações da atividade.

A narrativa para a atividade de orientação trazia como temática a preparação para uma missão na selva Amazônica, onde apenas aqueles que concluíssem a atividade com êxito estariam aptos a participarem. Assim, durante a atividade de orientação, os participantes deveriam encontrar itens de sobrevivência na selva (e.g., bússola, cantil e alimento), os quais foram distribuídos (virtualmente) junto aos pontos de localização da atividade de orientação. Dessa maneira, para encontrar as localizações e os itens, os participantes precisavam desvendar enigmas no formato de charadas e solucionar problemas relacionados com os conteúdos de Geografia, utilizando o aplicativo de RA, para então receberem as pistas e localizações que os levavam para as próximas fases.

Para desempenhar a atividade apresentada nesta investigação, os participantes foram reunidos em grupos distintos, disputando uns contra os outros em todas as áreas do Colégio. Nesta atividade cada grupo recebeu: a) um dispositivo móvel (tablet), que em cada uma das três fases da atividade de orientação foram utilizados para reconhecer os marcadores de realidade aumentada, aos quais estavam associadas informações e dicas sobre a resolução da atividade no formato de charadas; b) uma rosa dos ventos impressa, para que pudessem se localizar na atividade e utilizá-la para encontrar as direções indicadas em cada uma das três fases; e, c) uma orientação inicial indicando o ponto cardeal norte (na ausência de uma bússola real).

Para tentar motivar os grupos a completarem as fases e engajá-los na continuidade das atividades, também foram implementadas técnicas de gamificação, através de um ranking dos grupos, com a pontuação individual e fornecendo recompensas a cada progressão alcançada. Para a formulação do ranking, foram estabelecidos como critérios de desempate o menor tempo e o menor número de dicas solicitadas (cada dica solicitada equivalia a 30 segundos no tempo total do grupo solicitante). Todos esses recursos foram incorporados no aplicativo instalado no dispositivo móvel, dessa maneira o grupo poderia requisitar uma dica para auxiliar nas respostas das charadas encontradas em cada fase da atividade, ou então o grupo poderia 
responder a charada, e no caso de acerto, eram habilitadas as coordenadas para o próximo ponto de localização.

A atividade de orientação contou com três fases, em que os participantes avançaram conforme a resolução de charadas, as quais possibilitaram indicações para a navegação entre os pontos cardeais e a orientação das coordenadas vistas previamente em sala de aula. Portanto, a abordagem pedagógica que subsidiou o desenvolvimento desta atividade de orientação foi a Aprendizagem Significativa de Ausubel (2000), uma vez que, os alunos em um primeiro momento aprendiam os conceitos básicos sobre localização e orientações geográficas em sala de aula (conceitos subsunçores). $O$ experimento realizado teve como objetivo fazer com que os participantes utilizassem esses conceitos subsunçores para refletirem e raciocinarem durante os desafios apresentados na atividade em campo e conseguissem reforçar e/ou aprimorar o seu aprendizado, visto que foram requisitados a refletirem sobre os conceitos vistos em aula, para se localizarem e progredirem na atividade, consequentemente, permitindo estabelecer a relação entre teoria e prática.

\subsection{ASPECTOS METODOLÓGICOS}

O procedimento metodológico adotado para a condução desta investigação consiste em um estudo de caso, que teve como objetivo implementar uma atividade educacional no formato de jogo, integrando recursos e conceitos de RA, como uma alternativa de ensino-aprendizagem dos tópicos de localização e orientação geográfica.

Em relação ao design de pesquisa, definiu-se como não-experimental com pósteste, pois Petri et al. (2017) sugerem que neste tipo de investigação, o estudo de caso começa com a aplicação do jogo educacional propriamente dito e, em seguida, um questionário é respondido pelos alunos para a coleta dos dados, tornando possível a avaliação da qualidade do jogo com base nas percepções dos alunos. Para a coleta dos dados referentes às percepções dos participantes foi utilizado o modelo de avaliação de jogos educacionais (MEEGA+) (Petri et al., 2017) na modalidade de avaliação de jogos não-digitais, em que os estudantes expressaram as suas opiniões em um questionário que utiliza como forma de medição a escala Likert de 5 pontos, com alternativas de respostas entre Discordo Fortemente (-2) a Concordo Fortemente (2).

\subsubsection{Dados Demográficos}

Os estudantes foram convidados a participar desta atividade durante um período de aula (45 minutos). Os dados demográficos que representam estes participantes compreendem um total de 75 participantes, divididos em 17 grupos de até cinco alunos, sendo compostos por $51 \%$ participantes do gênero masculino e $49 \%$ feminino, todos cursando o sexto ano do ensino fundamental e com faixa etária menor de 18 anos. A respeito da experiência dos participantes com jogos digitais e não-digitais, o modelo MEEGA+ utilizado na coleta dos dados desta atividade, possibilitou uma análise sobre a frequência de uso de jogos pelos participantes, apresentando evidências significativas de que na categoria de jogos não-digitais, as alternativas que prevaleceram quanto à frequência de uso de jogos como tabuleiros e cartas, foram as opções que correspondem a frequência semanalmente (36\%) e raramente (34\%), seguidas por mensalmente $(20 \%)$, diariamente $(9 \%)$ e nunca jogou $(1 \%)$. 


\subsubsection{Design do Estudo}

Foram estabelecidas etapas que compreendem a elaboração do jogo e o atendimento aos requisitos característicos de atividades de orientação, a construção do aplicativo para dispositivos móveis, até a execução da atividade com os participantes, todas as fases contemplando os conteúdos de Geografia. Para melhor descrevê-las, as fases foram distribuídas em dois momentos "Construção do Jogo" e "Realização da atividade".

No primeiro momento, para realizar a construção do jogo e seus componentes (e.g., charadas, orientações, aplicativo e conteúdos de Geografia), foi realizado um levantamento de requisitos que deveriam compor o jogo como um todo. Para tanto, realizou-se uma entrevista com o professor da disciplina para esclarecer os conteúdos da atividade de orientação, a fim de contemplá-los no decorrer da atividade. Definidas essas informações preliminares, os autores foram a campo com o intuito de elaborar a atividade de orientação, definindo os pontos de marcação e determinando as distâncias entre os pontos de localização. Por fim, houve a construção de um aplicativo utilizando o software Unity para a plataforma Android, contendo as orientações para as próximas localizações e dicas para a resposta das charadas.

Após serem estabelecidos os conteúdos que o jogo abordaria e as funcionalidades do aplicativo, foi dado início ao segundo momento, que consiste na realização da atividade com os participantes, no qual foram reunidos em uma sala para a contextualização da missão que envolveria a atividade de orientação, sendo explicadas as regras do jogo e demais informações pertinentes, bem como foram organizados pelo professor em grupos de até cinco integrantes. Após as orientações sobre a atividade e o papel de cada membro do grupo (líder, "homem-passo" e "homem-bússola"), um grupo por vez realizou a atividade de orientação sendo acompanhado por um pesquisador observador. Ao finalizarem o percurso estabelecido para a atividade de orientação, os participantes responderam ao modelo de avaliação de jogos educacionais.

\subsubsection{Avaliação do Jogo Educacional}

Para a avaliação da atividade de orientação, foi utilizado um modelo de avaliação da qualidade de jogos não-digitais denominado MEEGA+, que de acordo com Petri et al. (2017) tem como objetivo analisar jogos educacionais com o propósito de avaliar a percepção da qualidade em termos de experiência do jogador e percepção da aprendizagem do ponto de vista de alunos e instrutores.

Para desempenhar a avaliação referente à experiência do jogador, os autores do modelo MEEGA+ definem os fatores de qualidade por um conjunto de oito dimensões, os quais envolvem a opinião do participante a respeito de: atenção focada, diversão, desafio, interação social, confiança, relevância, satisfação e usabilidade. Já na avaliação referente à aprendizagem percebida durante a realização do jogo, os autores subdividem em duas dimensões, as quais consistem em: a) aprendizagem a curto prazo, que tem como objetivo avaliar o efeito global do jogo sobre a aprendizagem dos alunos; e, b) objetivos de aprendizagem, que pode ser personalizada conforme os objetivos de cada jogo educacional, mas que frequentemente giram em torno da melhoria dos conhecimentos sobre os níveis cognitivos de lembranças, compreensão e aplicação. 


\section{ANÁLISE DOS RESULTADOS}

Para a avaliação do jogo educacional foi utilizado o modelo MEEGA+ (versão para jogo não-digital) (Figura 1), o qual possibilitou mensurar o jogo no contexto relacionado à qualidade percebida pelos participantes e também no âmbito da aprendizagem. Portanto, fundamentado nas percepções dos participantes foi possível avaliar 33 itens a respeito da atividade de orientação, que envolvem as seguintes dimensões:

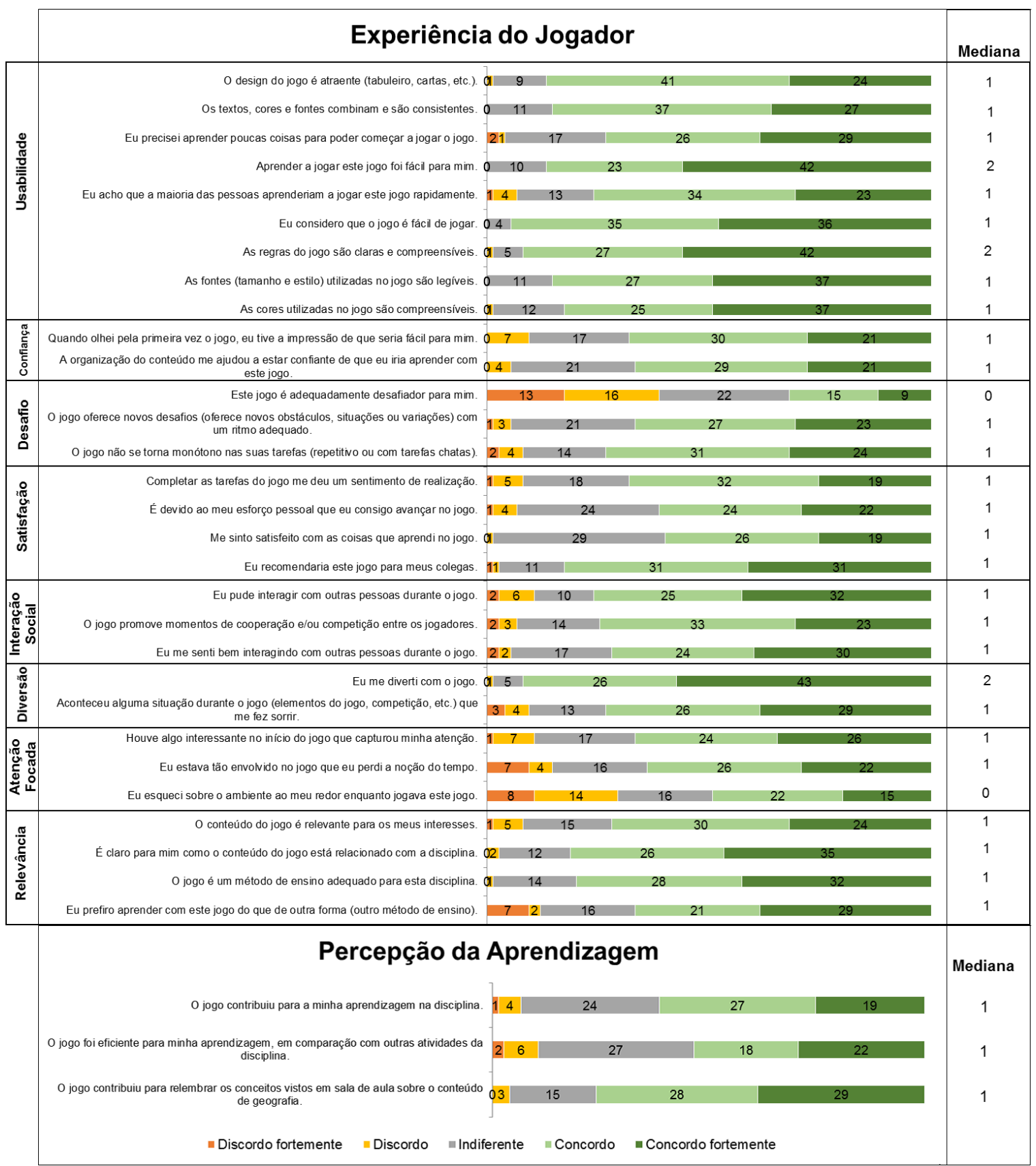

Figura 1. Resultados da Aplicação do MEEGA+ na Atividade de Orientação

Usabilidade: na dimensão que avaliou a percepção dos participantes quanto à usabilidade do jogo, a opinião dos participantes evidenciou uma predominante concordância, fornecendo indícios de que o design do jogo era atraente e que o mesmo 
fez uso de textos legíveis, fontes e cores compreensíveis e coerentes. A respeito do grau de aprendizagem requisitada para iniciar o jogo, a opinião dos usuários manteve-se de maneira favorável, na qual inclusive a mediana das avaliações atingiu a pontuação máxima, equivalente a dois pontos, demonstrando que adquirir as habilidades necessárias para realizar a atividade de orientação, foi fácil e não requisitou o aprendizado de muitos assuntos para iniciar o jogo, sendo este um resultado esperado pelos autores, em virtude desta modalidade de atividade já ter sido realizada com os participantes em outro momento. Esta perspectiva favorável (mediana de 2 pontos) manteve-se quando os participantes foram questionados em questões relacionadas às regras do jogo, que de acordo com os participantes estavam claras e compreensíveis, o que os ajudou a realizar a atividade de orientação e colocar em prática os conteúdos de Geografia vistos em sala de aula, tanto para desvendar as charadas e pistas incutidas na atividade como na navegação entre os pontos cardeais e fases do jogo.

Confiança: quando avaliada a dimensão de confiança do estudante em relação à participação na atividade de orientação, as opiniões prevaleceram positivas, com a mediana equivalente a 1 ponto em ambos os itens avaliados, sugerindo que a organização estabelecida para a realização da atividade, desde a apresentação do conteúdo, por meio de charadas e pistas relacionadas com a área de geografia, até a técnica de gamificação empregada para esta atividade, com fases, recompensas e premiações, contribuiu para o participante sentir-se confiante de que iria aprender com a atividade de orientação. Da mesma forma, esses aspectos corroboraram para uma boa primeira impressão dos participantes sobre o jogo, transparecendo a noção de que seria relativamente fácil realizar a atividade.

Desafio: já em relação à dimensão que aborda o quão desafiador foi realizar a atividade de orientação, os participantes expressaram suas percepções de maneira divergente, uma vez que no primeiro item avaliado, que estava relacionado ao desafio inerente ao jogo, a opinião dos estudantes foi equilibrada (com a mediana zero), indicando que uma grande parte das respostas foi de objeção ao critério de que o jogo era adequadamente desafiador ao participante. Além disso, através dos comentários dos participantes, também foi possível evidenciar que em muitos relatos os estudantes mencionaram que a atividade de orientação poderia contar com um maior número de pontos de localização, assim como o nível dos enigmas poderia ser aumentado. Por outro lado, nos outros dois critérios avaliados, os resultados se mostraram favoráveis, evidenciando que os participantes concordaram em sua maioria que a atividade de orientação apresentou novos desafios, através da configuração de fases implementadas para a atividade, com enigmas, charadas e pontos de localização com distâncias distintas, características que oportunizaram o entretenimento e a competição entre os grupos, com desafios e variadas situações e obstáculos.

Satisfação: a avaliação desta dimensão demonstrou uma positividade moderada na percepção dos estudantes, em virtude das medianas dos quatro itens avaliados ter permanecido com a nota de 1 ponto. A respeito desta dimensão, pode-se afirmar que em decorrência da implementação de fases, que possibilitaram os estudantes saírem em busca de pistas e pontos de localização, com recompensas a cada ponto encontrado, e.g., bússola, cantil e outros elementos que seriam utilizados durante a missão na Selva Amazônica, foi possível promover o sentimento de realização em cada etapa vencida pelo grupo na atividade. Ainda em relação ao sentimento de realização, foi possível observar que o grupo envolveu-se de tal maneira que além de ser evidente o esforço do 
grupo para alcançar a etapa final, cada integrante também demonstrou uma dedicação individual, a qual possibilitou avançar as fases do jogo, uma vez que os integrantes assumiram papéis durante a atividade e revezavam a cada ponto encontrado. Por exemplo, o líder era o responsável por organizar a equipe, carregar o dispositivo móvel e utilizar os recursos de RA; já o "homem-passo" mensurava a contagem de metros entre os pontos de localização existentes na atividade; por fim, o "homem-bússola" que orientava a equipe nos pontos cardeais através da rosa dos ventos recebida. Através dos papéis interpretados e da contextualização temática envolvendo uma missão com recompensas aos participantes, as percepções indicaram que os estudantes se sentiram satisfeitos com as circunstâncias que aprenderam no jogo e também se demonstraram favoráveis a indicarem a atividade de orientação realizada para outros colegas.

Interação Social: no que tange à dimensão de interação social dos participantes durante a realização da atividade de orientação, através da avaliação foi possível constatar que os participantes demonstraram-se positivos, com uma mediana de 1 ponto para cada um dos três itens mensurados. Em relação à essa dimensão, os participantes afirmaram que durante a atividade, interagiram com outras pessoas e que sentiram-se bem relacionando-se com os demais jogadores, aspecto que leva os autores a acreditarem que a distribuição dos papéis entre os integrantes do grupo foi fundamental para todos sentirem-se envolvidos e parte do grupo. Além disso, em virtude das técnicas de gamificação implementadas para a realização da atividade, assim como a temática descrita anteriormente, pode-se evidenciar que os estudantes foram favoráveis no entendimento de que o jogo promoveu momentos de cooperação entre o seu grupo e também de competição entre os demais grupos participantes (Figura 2).

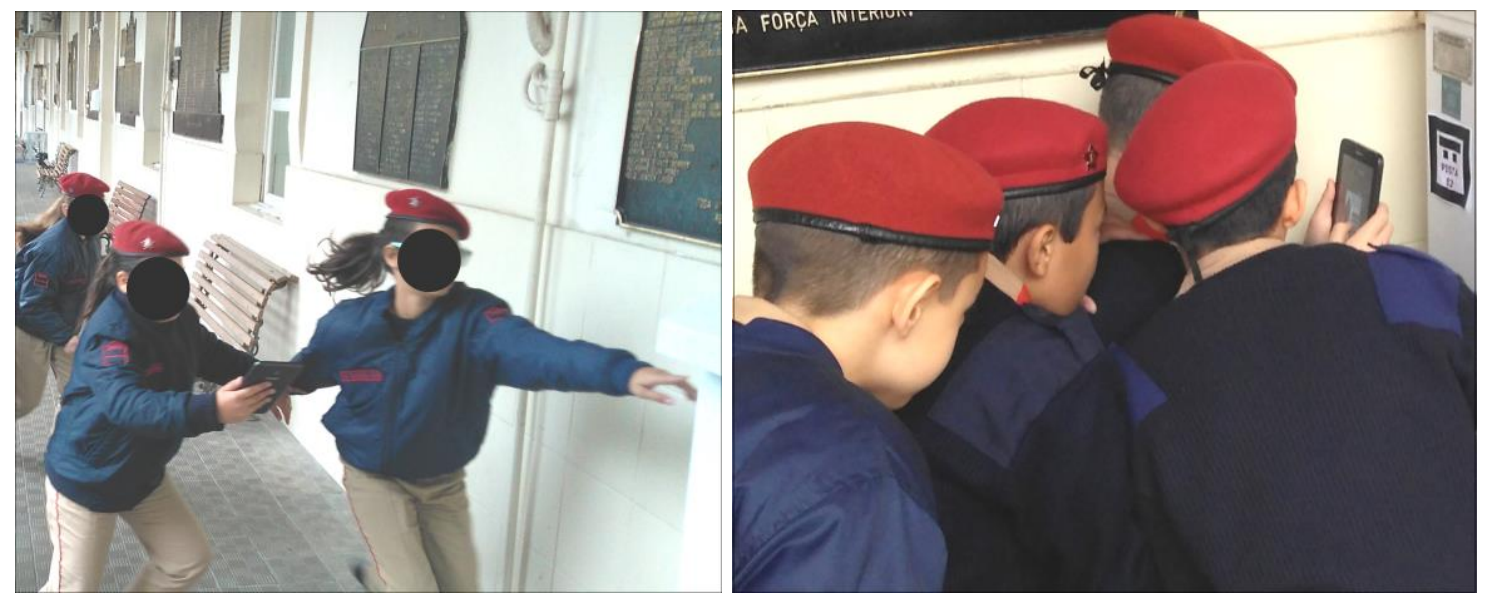

Figura 2. Participantes realizando a atividade de orientação

Diversão: em relação a avaliação da dimensão que compreende ao divertimento que o participante experienciou durante a atividade de orientação, os resultados foram satisfatoriamente positivos, com uma mediana de 2 pontos para o primeiro item avaliado e de 1 ponto para o segundo item. Neste quesito, através das percepções manifestadas pelos estudantes, foi possível qualificar que o jogo proporcionou momentos de diversão e, além disso, os participantes se mostraram favoráveis na afirmação de que durante a realização da atividade de orientação, aconteceram situações que os fizeram sorrir, aspecto que foi possibilitado por meio da descoberta e resolução de enigmas, das fases e da competição promovida entre os grupos, assim como as recompensas conquistadas com o empenho individual do participante e do grupo. 
Atenção focada: no que diz respeito à atenção empenhada pelos participantes para a realização da atividade de orientação, identificou-se uma divergência nas percepções obtidas na avaliação dos participantes. Nos dois primeiros itens avaliados, os estudantes se mostraram moderadamente positivos, em que ambas as medianas foram de 1 ponto, indicando que no decorrer da atividade de orientação, ocorreram situações interessantes e que capturaram a sua atenção, assim como também acreditaram estar tão envolvidos que perderam a noção do tempo. No entanto, em relação ao terceiro quesito avaliado, no qual atribuiu-se a mediana de zero, foi possível observar uma discrepância entre os estudantes sobre o item avaliado, o qual buscou apontar se os participantes haviam esquecido do ambiente ao seu redor enquanto realizavam a atividade de orientação. No que tange às percepções sobre o último item avaliado, os autores desta investigação entendem que ao responder esta questão, os participantes acreditaram que não poderiam perder o senso de localização no ambiente ao qual estavam, pois a atividade em questão necessitava justamente o contrário, de que esta habilidade estivesse aguçada, para que os mesmos encontrassem todos os pontos de localização o mais rápido possível, visto que a competição além de envolver a solução das charadas, também contemplava a realização da atividade no menor tempo possível.

Relevância: as percepções dos participantes quanto à relevância da atividade de orientação, demonstrou uma moderada aprovação dos estudantes nos quatro itens avaliados, os quais obtiveram a mediana de 1 ponto. Neste aspecto, os participantes demonstraram suas opiniões no sentido de que o conteúdo do jogo foi significante para os seus interesses. Além disso, também foi possível evidenciar que os estudantes apreciaram de maneira positiva a estratégia utilizada para relacionar o conteúdo da disciplina de geografia com a utilização de uma atividade lúdica, envolvente e com técnicas de gamificação, uma vez que os participantes afirmaram estar clara a forma como a atividade em questão estava relacionada com o conteúdo de geografia e indicarem que o método empregado para a atividade era adequado, por possibilitar uma procura aos pontos de localização, através da resolução dos enigmas e utilização dos conhecimentos obtidos em sala de aula para a navegação entre os pontos cardeais. E, por último, os participantes também expressaram de maneira positiva e equilibrada a opinião de que possuem preferência em aprender com estratégias semelhantes às utilizadas na atividade de orientação em comparação com outros métodos de ensino, evidenciando que a atividade foi eficiente naquilo que se propôs, de complementar o conteúdo visto em sala de aula. Tal afirmação segue os preceitos discutidos na abordagem pedagógica da aprendizagem significativa proposta por Ausubel, a qual foi empregada neste estudo com a intenção de fazer com que os participantes colocassem em prática os conceitos subsunçores vistos previamente na disciplina, tais como localização, coordenadas geográficas, entre outros, para responder aos desafios dispostos e aprimorar seu conhecimento nos tópicos abordados.

Aprendizagem: os três últimos itens avaliados, constituem a dimensão de aprendizagem compreendida pelos participantes na atividade de orientação, na qual a avaliação geral demonstrou-se moderadamente favorável à prática da atividade em questão, visto que a mediana nos três itens avaliados foi de 1 ponto. Nesta dimensão, os estudantes expressaram suas percepções de forma positiva no que diz respeito à aprendizagem, qualificando a atividade de orientação e indicando que a mesma contribuiu para a aprendizagem dos conteúdos relacionados à disciplina de geografia, assim como foi eficiente em comparação com outras atividades realizadas no decorrer 
do semestre. Outro ponto evidenciado com base nas avaliações dos participantes consiste na contribuição da atividade de orientação para auxiliar os estudantes a relembrarem dos conteúdos de geografia vistos em sala de aula, no qual os participantes se mostraram favoráveis, em virtude de o jogo requisitar que os alunos refletissem sobre os seus conhecimentos de geografia, para solucionarem os enigmas e encontrarem os pontos de localização distribuídos pelo Colégio.

\section{CONSIDERAÇÕES FINAIS}

Esta investigação demonstrou uma maneira eficaz de aliar o uso da tecnologia como ferramenta de auxílio no processo de ensino-aprendizagem de conteúdos relacionados à Geografia, através da combinação de dispositivos móveis e recursos de RA com uma atividade de orientação, proporcionando aos seus participantes uma reflexão na prática dos conteúdos apresentados em sala de aula sobre localização e orientações geográficas, a partir da integração da teoria de aprendizagem significativa e da gamificação.

Acerca das perspectivas futuras para esse estudo, os autores pretendem convergir as novas investigações na direção expressada nos comentários dos participantes, nos quais enfatizaram que a atividade de orientação deveria contar com um maior número de pistas (fases do jogo), assim como intensificar a dificuldade para encontrá-las. A partir dos testes realizados, os autores também observaram a necessidade de aprimorar o feedback, apresentando-o constantemente, a cada ação realizada pelo participante.

\section{REFERÊNCIAS}

Ausubel, D. P. (2000). The acquisition and retention of knowledge: A cognitive view. Kluwer Academic Publishers.

Calisto, A., Barbosa D. e Silva C. (2010). Uma análise comparativa entre jogos educativos visando a criação de um jogo para educação ambiental. XXI Simpósio Brasileiro de Informática na Educação (SBIE), p. 1-10.

Kato, H., Yamamoto, G., Miyazaki, J., Taketomi, T., Chen, A. e Santos, M. E. C. (2014). Augmented reality learning experiences: Survey of prototype design and evaluation. IEEE Transactions on Learning Technologies, 7(1), p. 38-56.

Netto, D., Silva, G., De Melo, H. e Da Costa, V. (2016). Geography History: Um aplicativo para auxílio ao ensino de Geografia. XXVII Simpósio Brasileiro de Informática na Educação (SBIE), p. 1-10.

Petri, G., Gresse von Wangenheim, C. e Borgatto, A. F. (2017). Evolução de um modelo de avaliação de jogos para o ensino de computação. $\mathbf{2 5}^{\circ}$ Workshop sobre Educação em Computação - Congresso da Sociedade Brasileira de Computação (CSBC).

Sabota, H. S. e Bueno, M. A. (2013). Trilha de orientação: aplicação de uma prática de ensino de cartografia para a compreensão dos conceitos da Geografia física na fase escolar. Revista Territorium Terram, 2(3), p. 84-97.

Thomaz, A. R., Maraschin, C., Zaniol, E. e Schuch, E. M. M. (2005). Dispositivos de imersão em ambientes de realidade virtual. Revista Brasileira de Informática na Educação (RBIE), 13(2), p. 21-32.

Webster, J. e Hackley P. (1997). Teaching effectiveness in technology-mediated distance learning. Academy of Management Journal, 40(6), p. 1282-1309. 